\title{
The Legal Practice and Solutions in Dispute of Non-written House Tenancy
}

\author{
Hongfan Chen \\ School of Law, University of Sydney, Sydney, 2000, Australia \\ 372946504@qq.com
}

Keywords: Non-written contract, House tenancy, Legal application, Deposit.

\begin{abstract}
An important reason why the leaseholder could not protect their right properly in dispute of house-leasing without written contract is that it lacks of written evidences. This reason may be a motivation that leads this essay. In this essay, to begin with, will explain the basis of legal in non-written contract and contract breaching dispute field and then will show the method of solutions and legal application when individuals face to the dispute of house tenancy of non-written contract. It means that can protect the legal rights of leaseholder by methods of quote. In the third section, it will be described a sample of the dispute of non-written contract housing lease which will be used to test the efficiency of the solutions.
\end{abstract}

\section{Introduction}

An important reason why the leaseholder could not protect their right properly in dispute of house-leasing without written contract is that it lacks of written evidences. This reason may be a motivation that leads this essay. In this essay, to begin with, will explain the basis of legal in non-written contract and contract breaching dispute field and then will show the method of solutions and legal application when individuals face to the dispute of house tenancy of non-written contract. It means that can protect the legal rights of leaseholder by methods of quote. In the third section, it will be described a sample of the dispute of non-written contract housing lease which will be used to test the efficiency of the solutions.

\section{The Basic Theory of Non-written Contract}

The Definition of Non-written Contract is that an agreement or appointment which is made by equal parties but they do not confirm contract through the type of written. In this section, constitute of non-written contract and the legal application of dispute of house tenancy will be represented.

According to the definition of the contract, non-written contract can be consist of the following sections [1]:

(1) The need for a promise or promises but not confirmed by the form of written.

(2) The agreement between two or more individuals should have equal legal status. This is the premise of the contract that it can be found in the Article Three of the Contract law of the People's Republic of China: Parties have equal status when they take participate in civil activities. It can be seen that the equal status should be described that the legal status is equal.

(3) The principle of voluntariness. According to Article Four of the Contract law of the People's Republic of China: The parties have a right which is allowed to them make agreement free and voluntary. In this case, any organizations and individuals should not interfere illegally the contract in any situation. This is the basic rules in the Contract Law.

(4) Promise or promises are requested to between the legal ability parties. In order to ensure the successful performance of the contract, the relevant person or persons should completely realize what they are doing and their behaviours are extremely under control by themselves. Behaviour of no capacity person or limited capacity person should be confirmed by their guardian if these two types of 
people want to make deal with others (According to the law, the behaviour of guardian can be regarded as the right of admitting retroactively).

In current legal practise, the argument which is aroused by the non-written contract majorly focus on the dispute of contract which is adjusted by the Labour Law and the situations that are not confirmed by regulations.

There are two rules can be found in Chinese legal system which can be viewed as solutions encountering the above situations. Firstly, according to Article Eighty Two of the Labour Contract Law of the People's Republic of China, if an employer concludes a written employment contract with an employee more than one month but less than one year after the date on which it started using the employee. It shall pay twice salary what the employee earns to him or her each month. The purpose of this rule is that protect the labour relationship through enhancing the sign of written contract. In law practise, it is more likely to explain the meaning of the rule from the result, which means it can be viewed as breaking the law unless the employer offers the written contract to their employee and conclude the contract, the employer can pay the double wage. To some extent, the rule of 'the compensation of double salary' can be regarded as a method to protect the interest of employee, to save resources of justice and to conduct the dispute between employer and employee more efficient.

On the other hand, according to Article Ten of Chinese Contract Law, there are three forms of contract can be concluded: the form of written, the verbal agreement and others. However, the dispute, which is triggered by verbal appointment, plays an important role in the life. The authority often harness Article Sixty One[2] and Sixty Two of the Contract Law [3] to resolve the dispute which is caused by some regular reasons such as quality, price, reward and the place of performance. Moreover, the principle whether one party conduct his or her major obligations and whether the obligation is accepted by the other side can be the basis of judgement when the argument focus on whether the contract is concluded or is performed.

\section{Law application of Non-written Tenancy Contract Dispute}

The dispute of house tenancy mainly can be found in three relationships of rights and obligations. Firstly, it is the conflict between leaser and renter, it also happens between subtenant and transferee. Finally, the argument can be happened between tenant and transferee. The dispute of non-written contract between these relationships can be performed the following situations.

The argument of appended materials is the most common problem between the parties. Under the civil law system, the agreement between parties is the first choice as the solution when the dispute of ownership of appended materials happens. If the parties never make some appointments, Article 223[4] of the Contract Law can be viewed as a sample that should be followed. According to this rule, it can be separated into the following cases. Firstly, if renter furnishes or adds ornamentals into the rental house or room without the permission, the householder can require the compensation or the reconversion. Secondly, if the parties make an agreement that the rental house or room can be furnished or addition to the lease item, but they are not decided the ownership of the addition, it can be settled to two methods in law practise. To begin with, the ownership of annexed item or items that can be restore to its original conditions belongs to the renter. In this case, the renter should undertake a restorable obligation as long as he or she damages the rental house because of their behaviour of removing the addition. Furthermore, when the annexed item or items cannot be removed, but the householder gives a promise that he or she is willing to harness the addition, considering the principle of freedom of contract. The householder could have the proprietary of this addition that only should be fulfilled two conditions: The tenancy term is expired and the householder pays the price of annexed item or items. Otherwise, the parties should be compensated the damage which can be paid by agreement between the parties or liability for fault.

Another common dispute is inclined to believe that is caused by rent and deposit. According to the Second Paragraph of Article Nine of the regulation of commercial property tenancy, increasing rent randomly is prohibited during the expiration of lease term. It means that increasing rent is limited for 
the purpose of protecting the renter's interest. However, considering the party autonomy principle, the behaviour of increasing rent normally cannot be viewed as illegal unless the judge think that is breaking the principle of autonomy. It may be because the rule which aims at forming the expiration of lease term is not regulated, the householder always can renew the contract to avoid Article of 213[5] and Article of 232 of contract law[6] and makes the profits. Moreover, the conception of deposit cannot be found in Chinese legal system because of the hysteresis of the law, which may damage the interest of the renter.

According to Article 215 of the Contract Law, the form of shall conclude the contract written when the lease period is more than six months. It can be regarded as the fixed-term contract unless the contract is not confirmed in the written form. In situation of non-term contract, the parties can cancel contract at any time as long as a reasonable notice can be referred. Thus, although the written form contract of housing tenancy plays a core role due to the regulations that are published by the authority, the definition of the successful performance of the contract in legal practice is that the parties fulfil the obligations that are concluded in the contract.

However, in market of house tenancy, as a mentioned, householder often requests some rents as a deposit when the renter moves into the rental house or room. It arouses an issue that the householder refuses to return the deposit when the contract successfully performs. Moreover, renter usually cannot get their money back owing to they cannot put the proof that the deposit is existed even the contract could not be proved that is real especially without the written form contract. This awaked situation will be discussed in the following section.

\section{Proof-providing Methods}

The evidence, basis of proving the fact of case, can be regarded as the core in lawsuit. Thus, how to use the evidences to prove the contract which is actual existing and performances successfully, how to prove the renter paid their bills, can be a crucial basis which is the fact the judge relies on during the law suit. It is why numerous experts believe that the core in lawsuit could be the evidence. Considering this, proof of verbal agreement usually uses the approach that actually performances to be the deciding evidence which may be proved that the tenancy contract is valid. This section will list three types of proof methods, which may help to identify the valid contract, or not when individuals encounter the dispute of house leasing, which is based on Article 63 of Civil Procedural Law of People's Republic of China [7].

\section{Documentary Evidence}

The Documentary evidence, which presents as text materials and other carrier, is the one of proof for the purpose of fact identification during the law suit and its records or expression of ideological content which is directly relevant to the case itself can prove the truth. In practise law, whether rent and deposit are paid can be an important factor to be evidence that may decide the parties to be a winner or not. The following approaches can be used as the documentary evidence. Firstly, renter can transfer bills through bank account to pay rent and deposit but it should be noted like the use of money, description of deposit and rent of exact month. At the same time, the method of payment should be formed when the parties make an agreement. It means that reserving bank account which belongs to the householder to remit money automatic if it possible will be a best approach to avoid dispute and hold effective evidence just in case. Moreover, if parties make appointment that pay bills by cash, requiring householder to write the receipt could be more helpful when the argument happens. However, documentary evidence does not have strong evidential effect in China due to the law that the parties have to exhibit the evidence to the relevant authority for purpose of checking effect and whether it fakes. 


\section{Testimony of Witnesses}

Testimony, a part of seven types of legal evidence, can be identified the words which is based on facts from individuals' position. It can be used in the following two situations. Firstly, when the agreement cannot be signed in formal between the parties, or the parties cannot submit the efficient bank transfer record or records, the words of witness can be basis which may lead the truth after the relevant authority verify it. In addition, testimony can be the secondary proof to help the judge to verify the fact of case.

\section{Audiovisual Materials}

The electronic equipments, such as tapes, video tapes, film or computer, which can be used to save images, graphics and audio, can be a proof of the case facts, which could be referred as audio-visual material. It is worth nothing that the audiovisuals should be combined with other evidences during the lawsuit. In practice law, the parties can record their agreement like video as evidence which can prove that there is an agreement existing or it performs correctly if it necessary. For example, saving the chatting record online and recording the dialogue between the parties could be a method for purpose of saving evidence.

\section{Law Application in Dispute of Non-written Contract}

'Can be returned' is one of the most important features of deposit. It is supposed to be an obligation of householder when the tenancy performs completely and the usufruct comes back to householder. Unfortunately, deposit refund currently is not formed in Chinese legal system. In this case, deposit refund system in the USA may be used as a reference to discuss how to solve the problem of deposit refund without formal contract under the Chinese legal system.

How to prove the tenancy contract efficient and existed is the essential problem, which may lead the direction of case. According to the principle of 'who claim, who prove', the one side of parties could use some records like payment of bank account record. It is to prove the rent or deposit is paid or is accepted, rely on letter, phone call recording and chatting record as evidence to prove that the parties have been made an agreement or agreements express or implied, require the witnesses as evidences.

The second problem, which should be discussed, is deposit refund problem. According to American law: 'deposit only can be used to pay the rent which defaulted by renter or to compensate the actual damage of rental house or room.' The purpose of this rule is to avoid householder that uses plenty of excuses to refuse return deposit. For example, in case of Smolen v. Dahlmann Apartments .Ltd [8], householder refuses to refund deposit because rental house had to be cleaned. 'House is dirty' cannot be a reason, which impede renter, cannot get refund because it is not real damage. This is reason why the deposit was sentenced to return to Smolen.

\section{Solution System}

This section will combine good laws which are published by developed countries like America and discuss how to build the solution system of deposit refund which is not be regulated in China. There are two main parts should be mentioned.

(1) The amount of refund

As a mentioned before, if renter completely performs him or her obligation, the full of the deposit should be refund. On the contrary, if the obligation is not carried out properly, for example, rental house is damaged because of renter that means a reasonable percent of deposit could be deducted.

(2) Date of refund

- The period of refund time

Considering that interest of renter has to be protected as soon as possible and whether house or room damaged and compensation need time to be confirmed, the period of refund, time cannot be too short 
and cannot be too long either. In America, it depends on which states the case happens. For instance, in Arizona, the period is formed in fortnight and forty-five days is regulated in Indianan law. However, mostly, it is be regulated in thirty days.

- The start date of refund period

Normally, it can be separated to three types. Firstly, it starts at that the house or room key is back to householder. Secondly, use date of termination of contract as the first day to count. In addition, when contract is completed and renter gives the address to householder to return deposit, the date period could be started. Considering the rule, which is related to no-term contract, counting date that starts when contract is completed, will be more suitable.

- Legal consequence

The purpose of setting rules that always can be regarded as making sure that people's interest can be protected and the justice can be fulfilled. In other word, the perfect method to achieve the right of renter, is allowing people require the compensation. It also can be an alert to force householder to obey rules. The specific number of compensation can depend on how much interest was damaged to penalty by segment.

\section{Example of Dispute of Non-written Contract}

\section{(1) Preview}

Leaser A published rental information on the website and then made an agreement with renter B through the social internet: B prepaid four weeks' deposit when the contract performed completely and B finished the obligation then A returned the deposit in three days. B agreed, transferred deposit through bank account and descried it was deposit. Householder A expressed to receive deposit and promised the house would be cleaned when B checked in and it looked same just like he posted online. In addition, the promise has been made between $\mathrm{A}$ and $\mathrm{B}$ : The written contract should be signed when the leasing house is delivered. However, A required B to pay another eight weeks' rent and used four weeks' rent as a deposit because leaser a thought that the original deposit was not enough. B raised an objection and A ignored it for reason 'it is local custom' then A refused to sign formal contract for reason ' $B$ is so annoying' and required B to move out immediately as a threaten unless B paid another bills. B was be forced to compromise with this request and paid eight weeks' rent. After that, B insisted to sign contract and A ignored it again. At the same time, the rental house B moved in has been found that was different to the house where has been posted online. B felt that his right has been offended and found A to require his money back. A refused and the dispute happened.

\section{(2) Analysis of dispute}

This above descried was a typical tenancy dispute of non-written contract. Whether the agreement what was the parties made online could be viewed as a contract which was not confirmed by written form was an essential factor should be clear at first. To begin with, the character of online advertisement had to be defined. According to Article fifteen of Contract law of People's Republic of China: 'Invitation for offer is a wish which hope others to send an offer to invite and make an agreement. A delivered price outline, announcement of auction or commercial advertisement is an invitation to offer.' It requires that bid inviter respond to offer which can be viewed as establishment of contract. It not exists any right and obligation in invitation for offer which is the typical difference between offer and invitation for offer. In addition, the audiences of invitation for offer is aiming at non-special or special most individuals and the offer is only sent to special individual or group. In this case, the behaviour, which posted the commercial advertisement online of leaser A, cannot be viewed as sending offer to others but it can be regarded as invitation to offer. However, the response of receiving offer, which is from renter B, could be viewed as making a promise. This 'promise' behaviour, according to Article thirteen of Contract Law, can be viewed as the establishment of contract. In addition, although contract law regulate the contract of tenancy should be concluded by written form, the following article admit that non-written contract can be regarded as non-term contract. 
In conclusion, the chatting record which is related to rent, tenancy term and specific conditions actually could be seen the non-term tenancy contract.

Secondly, the original contract did not definite that the deposit should be paid again and A made a promise to refund deposit. However, according to the principle of freedom of contract (Article Three of Chinese Contract Law), householder A's behaviour what required B to pay another bills actually could be seen that sent a new offer to B and B defaulted it. It could be regarded as the new agreement has been established between A and B. Fortunately, although contract is regulated by civil law, which is extremely to obey the principle of autonomy of, will. It has a rule which is aiming at avoid the principle is abused by individuals or organisations that the parties have a right which is made deal totally by themselves unless it against the law, any individuals and organisations cannot intervene it (Article Three of Contract Law). In this case, the behaviour that a threatened B to compel B to pay another bills and the new contract actually built which was based on forcing people. It means that this could be viewed as the situation where can find in Article Fifty Four of Contract Law: If the contract belongs to contract subject to amendment or cancellation, the parties, in this case is renter B, may petition the court or an arbitration for amendment or cancellation of contract.

Furthermore, there are two thinking analysis as mock for the regulation of deposit because in current deposit regulation has not stipulated in Chinese legal system.

- Reference the deposit rules of the USA:

Renter B may apply requirement to the People's Court or ask for arbitration to return double deposit and four weeks' rent.

- Analogy Suitability

Analogy suitability is a supplement which aims at fill the lack of law when law made no stipulation. Although there is different definition between tenancy and sales contract, which means that the object in tenancy contract is the right of use in a certain period and the object in sales contract is property. In this case, the tenancy contract can be viewed as the sales contract in broad sense. It means that the deposit can be viewed as bargain money and rent can be viewed as the spare money. The rental house can be regarded as subject matter. In this situation, the solutions of dispute can be found in regulation of sales contract.

\section{Conclusion}

Owing to the lag of law itself, the dispute of tenancy happens frequency. It leads renter's interest has been damaged fearful but it still cannot be fixed. Considering this, some foreign theories and good legal systems can be used for reference. It means that house tenancy legal system should be built and improved for purpose of protecting the parties' interests. It is improving the market of property.

\section{References}

[1]. Stephen Graw, an Introduction to the Law of Contract, published in Sydney by Lawbook, fifth edited at 1st November, 2004, p.27.

[2]. National People's Congress of China, Contract Law of People's Republic of China, 61, 1999.

[3]. National People's Congress of China, Contract Law of People's Republic of China, 62, 1999.

[4]. National People's Congress of China, Contract Law of People's Republic of China, 233, 1999.

[5]. National People's Congress of China, Contract Law of People's Republic of China, 213, 1999.

[6]. National People's Congress of China, Contract Law of People's Republic of China, 232, 1999.

[7]. National People's Congress of China, Contract Law of People's Republic of China, 63, 1999.

[8]. SMOLEN v. DAHLMANN APARTMENTS, LTD. Case No. 59750. 1983.

[9]. http://www.leagle.com/decision/1983235127MichApp108_1220/SMOLEN\%20v.\%20DAHLM ANN\%20APTS.,\%20LTD. 